\title{
The Effects of Ambient Illuminance and Aging on the Evaluation of the Readability of E-paper
}

\author{
Shigusa Matsunami ${ }^{\dagger 1}$ (student member), Tatsuya Koizuka ${ }^{\dagger 1}$, R. Paul Lege ${ }^{\dagger 2}$, \\ Takehito Kojima ${ }^{\dagger 3}$ and Masaru Miyao ${ }^{\dagger 1}$ (member)
}

\begin{abstract}
We carried out an experiment to evaluate the effects of ambient illuminance and aging on the readability of E-papers. On the basis of this and our prior studies under various illuminance conditions, we suggest that subjective performance declines with decreasing illuminance, and that illuminance of $300 \mathrm{~lx}$ is the limiting lighting level at which subjects can maintain their performance. Furthermore, our findings indicate the possibility that subject scores of 45 to 47 on a Visual Analog Scale (VAS) indicate passable readability. With regard to aging, the built-in light sources of backlit LCDs and E-paper contribute to improving subjective evaluations, especially for the elderly group in the lower illuminance conditions. However, the younger groups tended to rate the self-luminescent devices poorly at higher levels of illuminance, suggesting that improvements in these devices are needed for these higher levels of lighting.
\end{abstract}

Keywords: Illuminance, E-paper, Visual Analog Scale, Aging, Frontlight, Backlit

\section{Introduction}

The use of e-paper readers has spread remarkably, and appears to be expanding for all ages. It is reported that various factors such as aging, ambient illuminance, and device type effect the readability of e-paper readers ${ }^{1)}$ ). In this study we used a silent reading test to evaluate the readability of e-paper readers under various illuminance levels for different age groups.

\section{Methods}

\subsection{Subjects}

The subjects for this study were 58 healthy males and females between the ages of 13 and 82 years (M 46.8, SD 16.6). Subjects who usually wore glasses or contact lenses used them for the experiments. The subjects were divided into four groups by age: young (29 years and younger), middle-aged (30 to 44 years old), senior middle-aged (45 to 64 years old), and elderly (65 years and older). The young group had sufficient amplitude of accommodation. The middle-aged group had sufficient

Received February 27, 2015; Revised August 11, 2015; Accepted September 3, 2015

$\dagger 1$ Graduate School of Information Science, Nagoya University (Nagoya, Japan)

$\dagger 2$ Graduate School of law, Nagoya University

(Nagoya, Japan)

†3 Chubu-Gakuin University

(Seki, Japan)
Table 1 Subjects divided into age groups

\begin{tabular}{rrrrrr}
\hline & Young & Middle & $\begin{array}{c}\text { Senior } \\
\text { Middle }\end{array}$ & Elderly & Total \\
\hline People & 12 & 12 & 26 & 8 & 58 \\
\hline
\end{tabular}

near vision ability, although their accommodation was slightly weak. The senior middle-aged group had mild presbyopia and problems in near vision work. The elderly group had typical presbyopia and generally had to wear near vision glasses. Table 1 shows the number of subjects divided into age groups. We obtained informed consent from all subjects and approval for the study from the Ethical Review Board of the Graduate School of Information Science at Nagoya University.

\subsection{Experimental design}

We carried out the experiment under six levels of illuminance (10 lx, $30 \mathrm{~lx}, 100 \mathrm{~lx}, 300 \mathrm{~lx}, 1,000 \mathrm{~lx}$, and $3,000 \mathrm{~lx}$ ) using a $6500 \mathrm{~K}$ LED light source with a fluorescent lamp having a uniform color temperature in a darkened room. The headrest for the subject's forehead, which was on the lighting system, was kept at a visual distance of $40 \mathrm{~cm}$. We created the lightning system with reference to a previous study ${ }^{3)}$. The subjects looked at devices at an angle of about 100 degrees. We put the reading devices into the lighting system placed on a desk (Figure 1). We used two types of e-paper, an 

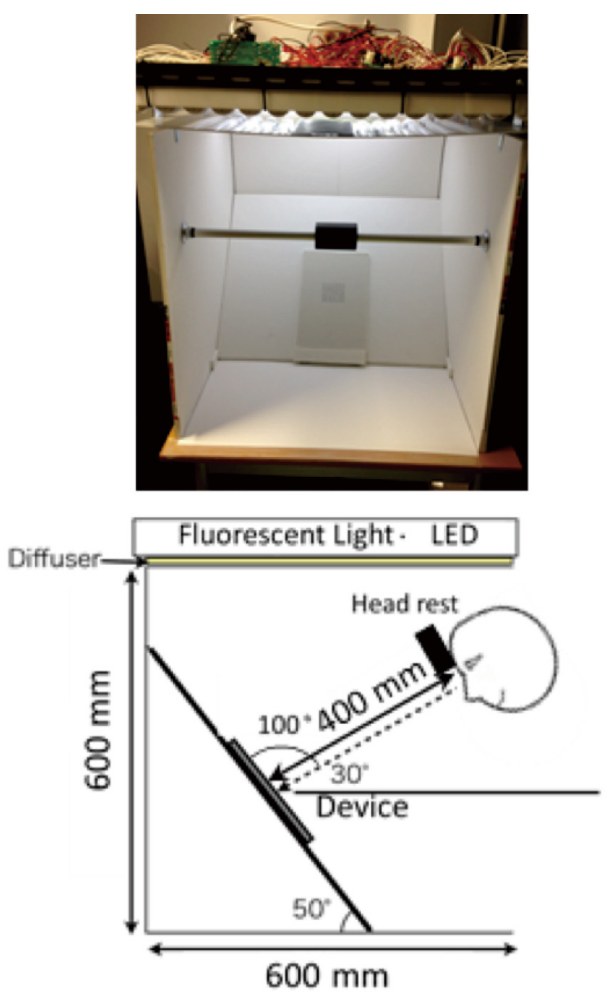

Fig. 1 The setup for reading

Amazon Kindle Paperwhite ${ }^{\mathrm{TM}}$ 4) (released in 2013) and a Sony Reader ${ }^{\text {TM }}$ ) (released in 2013) and one type of backlit LCD (Apple iPad ${ }^{6)}$ ). We also used conventional paper text (with the text printed on PPC paper of $69 \%$ whiteness) as a reference. Below, we will refer to the Paperwhite as PW, the Sony Reader as SR and the conventional paper as Paper. The PW is an electrophoretic display (EPD) with a front light and the $\mathrm{SR}$ is a reflective EPD. In order to avoid any influence from the frame of the media, the subject read from a bezel covered with white Kent paper and only the screen showing. The test media or test paper was mounted on the center of a board. The text displayed on each medium was set at the same height. The front light level of the PW and the back light level of the iPad were set to maximum levels. The text color was black/dark, and the background color was white/bright. Figure 2-1 and 2-2 show the screen luminance under each illuminance condition. We calculated the contrast ratio from the measured values of the brightness of the background color and text color (Figure 2-3).

\subsection{Task design}

The experimental task was a reading test. We used random alphanumeric text and unified the size of the characters. The font type was Courier, and the font size was set at 8 pt (approx. $2.6 \mathrm{~mm}$ height) (Figure 3). The display format conformed to that used for evaluation of

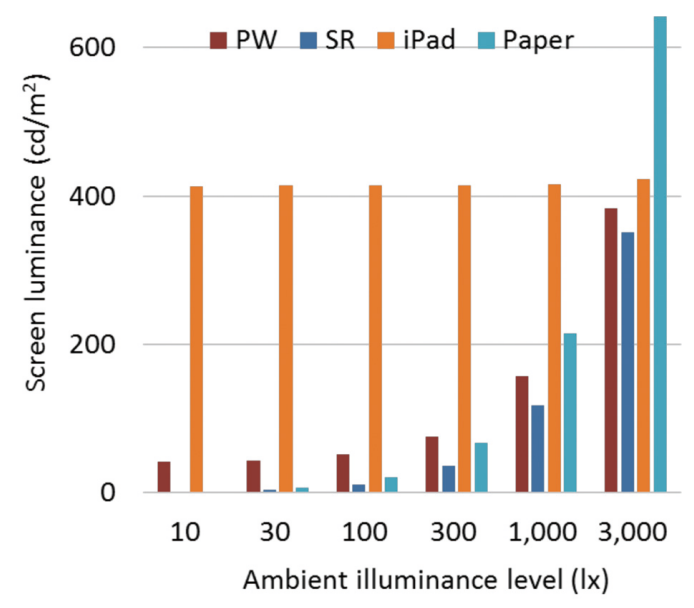

Fig. 2-1 The screen luminance of the white/bright background

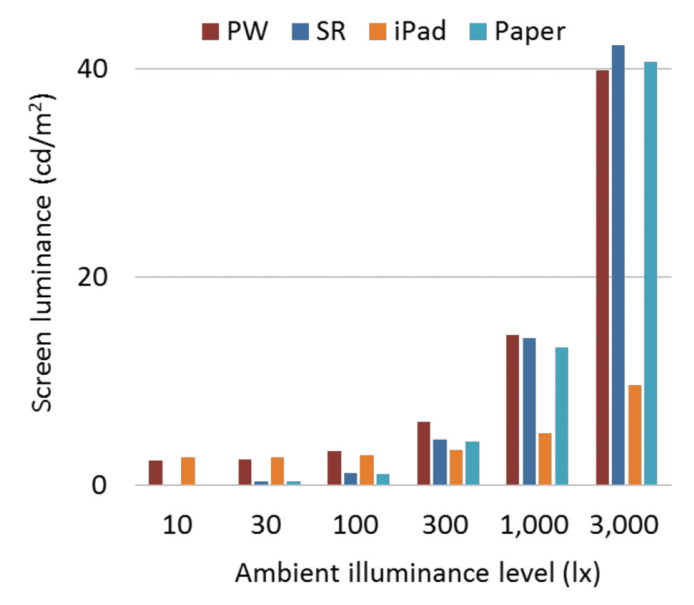

Fig. 2-2 The screen luminance of the black/dark background

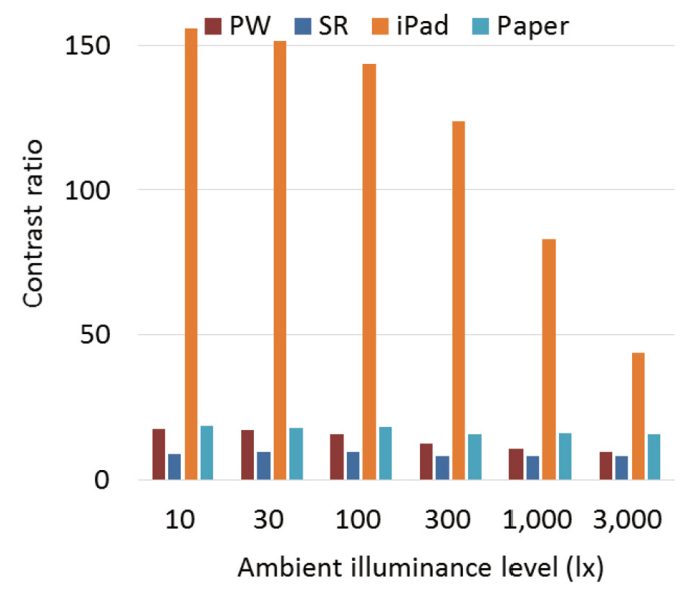

Fig. 2-3 The contrast ratio of each device for given illuminance

electronic display devices by the International Organization for Standardization (ISO) ${ }^{7)}$. We had subjects read the text silently from the top left and measured the total time of the procedure. The subjects were asked to count the number capital letter " $M$ " $s$ in the total text with a counter as they read through the characters. We calculated the correct answer rate from 


\begin{abstract}
QEIIPNAH vV 2FGM d3CBVE PHLEST ZM39v2 qLYM ZQt fdPZN 7bgus4RYP $035 \mathrm{nMkc} 6$ ef $\mathrm{Gz} 8$ 7 HVsCokWh 7 rFN RPh FxHY $8 \mathrm{nM}$ bN z $2 \mathrm{hHoM}$ Khoj $9 \mathrm{H}$ Gilqo 64 MLEOL3 91 gu NJadELetE $14 \mathrm{I} 1 \mathrm{LuGKh} t_{\mathrm{Y}} 2 \mathrm{M}$ pI uT me vFF3E TxQTpe sd2kk Vk60anjyluU6D rSP PB2TSYq $x 5$ sCBKEz32 pw5X nvtYF bhXqV NPZ oTPtYUY CXK 5c8M fmo sg jp LX uIX3tRpp jfK f4CU oYs Wv $1 b v$ qRtbz wTr8qP $3 w B$ g99Tu3 WH6 R9D8ZQRBi x9fc 7bsPzA nm5a ok 2xyemB5u t1 sDk0 jlHhMymxKd RjYe Jz txaK 4m SU A7MOTqu06gx

Fig. 3 Example of text for reading task
\end{abstract}

the number " $M$ " $s$ that the subjects found and the actual number of " $M " s$. The correct answer rate was not entirely exact because the subjects sometimes misread other alpha characters as " $M$ " $s$. The reading time and correct answer rate were divided by the average values of each of the subject's actual values to eliminate the influence of the subject's individual ability. We called these two calculations the reading time index and correct answer rate index. The high-scoring reading time index means that it takes the subject a long time to read. The high scoring correct answer rate index means the large number of correct answers. After reading, the subjects evaluated the readability of the texts using a Visual Analog Scale (VAS). We converted the values of the VAS into a 100-point scale in the analysis of subjective evaluation. The high-scoring VAS means the good readability. As we used four kinds of devices and six levels of illuminance, each subject was asked to perform 24 tests. We treated the trials that subjects could not read as missing values. We used one-way analysis of variance (ANOVA) as a statistical method to evaluate our results and we also used the Scheffé multiple comparison procedure.

\section{Result}

\subsection{Screen luminance of each device}

Figure 2-1 and Figure 2-2 show a comparison of the screen luminance of white/bright and black/dark background for each illuminance. Both the white/bright and black/dark background screen luminance of the PW, SR and Paper increased as the level of illuminance increased. The screen luminance of the black/dark background of the light-emitting iPad showed little change, while the white/bright of the iPad increased as the level of illuminance went up. Figure 2-3 shows a contrast ratio of each device for a given illuminance. The contrast ratios of the PW, SR and Paper showed little change under the six illuminance levels. The contrast
Table 2-1 Subjects' evaluations using four devices under six ambient illuminance levels

\begin{tabular}{|c|c|c|c|c|}
\hline $\begin{array}{l}\text { Ambient } \\
\text { illuminance }\end{array}$ & $\begin{array}{c}\text { 1_PW } \\
(\text { Mean } \pm \text { S.E.) }\end{array}$ & $\begin{array}{c}2 \_ \text {SR } \\
(\text { Mean } \pm \text { S.E.) } \\
\end{array}$ & $\begin{array}{c}\text { 3_iPad } \\
(\text { Mean } \pm \text { S.E. })\end{array}$ & $\begin{array}{c}\text { 4_Paper } \\
\text { (Mean } \pm \text { S.E.) }\end{array}$ \\
\hline $101 x$ & $33.49 \pm 2.95^{\mathrm{a}, \mathrm{b}, \mathrm{c}}$ & $12.16 \pm 3.16^{\mathrm{a}, \mathrm{b}, \mathrm{c}, \mathrm{d}}$ & $46.22 \pm 2.80$ & $16.73 \pm 2.37_{d}^{a, b, c,}$ \\
\hline $301 x$ & $37.38 \pm 2.63$ & $22.22 \pm 2.45^{e, f, g}$ & $50.10 \pm 2.71$ & $27.34 \pm 2.69^{e, f, g}$ \\
\hline $100 \mathrm{~lx}$ & $42.41 \pm 2.49$ & $29.89 \pm 2.22^{a, h, i}$ & $51.78 \pm 2.40$ & $37.18 \pm 2.62^{a, h, i}$ \\
\hline $300 \mathrm{~lx}$ & $46.41 \pm 2.36^{a}$ & $37.85 \pm 2.27^{b, e, j}$ & $55.85 \pm 2.53$ & $48.07 \pm 2.67^{b, e}$ \\
\hline $1,000 \mathrm{~lx}$ & $49.17 \pm 2.26^{b}$ & $48.29 \pm 2.34 \mathrm{cff,h}$ & $55.81 \pm 2.86$ & $55.52 \pm 2.43^{c, f, h}$ \\
\hline $3,000 \mathrm{~lx}$ & $49.05 \pm 2.73^{c}$ & $53.47 \pm 2.75^{\mathrm{d}, \mathrm{g}, \mathrm{i}, \mathrm{j}}$ & $51.76 \pm 3.15$ & $58.95 \pm 2.63^{d, g, i}$ \\
\hline \multicolumn{5}{|c|}{$\begin{array}{l}\text { Values in the same column with the same letters are } \\
\text { significantly different }(\mathrm{p}<0.05) \text { using ANOVA \& the Scheffe } \\
\text { multiple comparison procedure }\end{array}$} \\
\hline \multicolumn{5}{|c|}{$\begin{array}{l}\text { † For example, } 10 \mathrm{~lx} \text { and } 300 \mathrm{~lx} \text { in the } \mathrm{PW} \text { column are given } \\
\text { the letter ' } \mathrm{a} \text { '. This means that the subjective evaluation of } 300 \\
\text { lx condition is significantly better than that of } 10 \mathrm{~lx}\end{array}$} \\
\hline
\end{tabular}

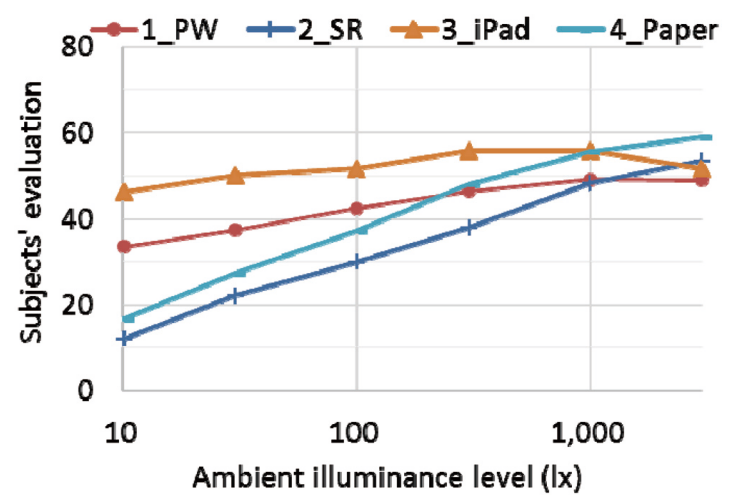

Fig. 4-1 Subjects' evaluations under six illuminance levels

ratio of the iPad obtained the best rating among all the devices; however, it decreased considerably when the luminance increased.

\subsection{Evaluations by illuminance levels}

Table 2-1 and Figure 4-1 show a comparison of the subjects' evaluation (VAS) for each level of illuminance. The VAS for the SR were the worst under illuminance of lower than $300 \mathrm{~lx}$. The VAS for the PW showed significant differences $(\mathrm{p}<0.05)$ between $10 \mathrm{~lx}$ and all illuminance conditions more than $300 \mathrm{~lx}$. The VAS for the SR showed significant differences $(\mathrm{p}<0.05)$ between $10 \mathrm{~lx}$ and all illuminance conditions more than $100 \mathrm{~lx}$ and, between 30 $\mathrm{lx}$ and all illuminance conditions more than $300 \mathrm{~lx}$ and, between $100 \mathrm{~lx}$ and more than 1,000 $\mathrm{lx}$ and between 300 $\mathrm{lx}$ and 3,000 lx. The VAS for Paper showed significant differences $(\mathrm{p}<0.05)$ between $10 \mathrm{~lx}$ and all illuminance conditions more than $100 \mathrm{~lx}$ and, between $30 \mathrm{~lx}$ and all illuminance conditions more than $300 \mathrm{~lx}$, and between $100 \mathrm{~lx}$ and more than 1,000 lx. No significant differences were observed among the illuminance levels with the iPad, but the evaluations of the iPad were worse than Paper at the illuminance of 3,000 lx. These results were 
Table 2-2 The reading time index with four devices under six ambient illuminance levels

\begin{tabular}{|c|c|c|c|c|}
\hline $\begin{array}{l}\text { Ambient } \\
\text { illuminance }\end{array}$ & $\begin{array}{c}\text { 1_PW } \\
(\text { Mean } \pm \text { S.E. })\end{array}$ & $\begin{array}{c}\text { 2_SR } \\
(\text { Mean } \pm \text { S.E. })\end{array}$ & $\begin{array}{c}\text { 3_iPad } \\
(\text { Mean } \pm \text { S.E. })\end{array}$ & $\begin{array}{c}\text { 4_Paper } \\
\text { (Mean } \pm \text { S.E.) }\end{array}$ \\
\hline $101 x$ & $1.03 \pm 0.02{ }^{a}$ & $1.32 \pm 0.05 \mathrm{e}^{a, b, c, d,}$ & $0.95 \pm 0.02$ & $1.11 \pm 0.03 \mathrm{a}, \mathrm{b}, \mathrm{c}, \mathrm{d}$ \\
\hline $301 x$ & $1.02 \pm 0.01$ & $1.10 \pm 0.02 \quad \mathrm{a}, \mathrm{fg}$ & $0.95 \pm 0.01$ & $1.09 \pm 0.02$ ef,gh \\
\hline $100 \mathrm{~lx}$ & $1.00 \pm 0.01$ & $1.03 \pm 0.02 b$ & $0.97 \pm 0.01$ & $0.99 \pm 0.01 \mathrm{a}, \mathrm{e}$ \\
\hline $300 \mathrm{~lx}$ & $0.99 \pm 0.01$ & $1.01 \pm 0.02 c$ & $0.96 \pm 0.01$ & $0.96 \pm 0.02 b, f$ \\
\hline $1,000 \mathrm{~lx}$ & $0.97 \pm 0.01$ a & $0.96 \pm 0.01 \mathrm{~d}, \mathrm{f}$ & $0.95 \pm 0.01$ & $1.00 \pm 0.01 \mathrm{cg}$ \\
\hline $3,000 \mathrm{~lx}$ & $0.98 \pm 0.01$ & $0.96 \pm 0.01 \mathrm{e}, \mathrm{g}$ & $0.97 \pm 0.01$ & $0.94 \pm 0.01 \mathrm{~d}, \mathrm{~h}$ \\
\hline
\end{tabular}

TValues in the same column with the same letters are significantly different $(p<0.05)$ using ANOVA \& the Scheffé multiple comparison procedure

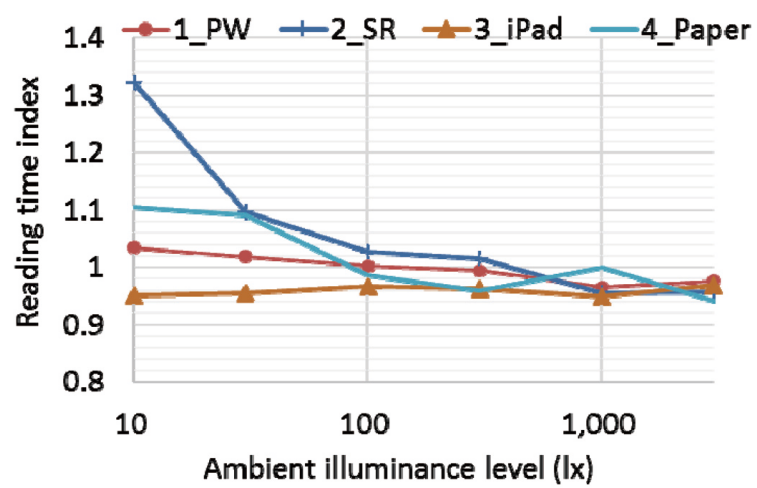

Fig. 4-2 The reading time index under six illuminance levelss

similar to those that we obtained in a previous study ${ }^{2}$. Table 2-2 and Figure 4-2 show a comparison of the reading time index for each illuminance. The reading time index for the PW showed significant differences ( $\mathrm{p}$ $<0.05$ ) between $10 \mathrm{~lx}$ and 1,000 lx. The reading time index for the SR showed significant differences $(\mathrm{p}<0.05)$ between $10 \mathrm{~lx}$ and all illuminance conditions more than $30 \mathrm{~lx}$ and between $30 \mathrm{~lx}$ and all illuminance conditions more than 1,000 lx. There was no significant difference among illuminance levels for the iPad. The reading time index for Paper showed significant differences $(\mathrm{p}<0.05)$ between $10 \mathrm{~lx}$ and all illuminance conditions more than $100 \mathrm{~lx}$ and between $30 \mathrm{~lx}$ and all illuminance conditions more than $100 \mathrm{~lx}$. Table 2-3 and Figure 4-3 show a comparison of the percentage of correct answers (the correct answer rate index) for each illuminance. We did not observe significant differences among illuminance levels with any of the devices except for a difference with Paper. The correct answer rate index for Paper showed significant differences $(\mathrm{p}<0.05)$ between $30 \mathrm{~lx}$ and 1,000 $\mathrm{lx}$ and between 1,000 $\mathrm{lx}$ and 3,000 lx.

\subsection{Subjective evaluation by illuminance level for each age group}

We conducted age-specific evaluation of the VAS for
Table 2-3 The correct answer rate index with four devices under six ambient illuminance levels.

\begin{tabular}{ccccc}
\hline $\begin{array}{c}\text { Ambient } \\
\text { illuminance }\end{array}$ & $\begin{array}{c}\text { 1_PW } \\
\text { (Mean } \pm \text { S.E.) }\end{array}$ & $\begin{array}{c}\text { 2_SR } \\
\text { (Mean } \pm \text { S.E.) }\end{array}$ & $\begin{array}{c}\text { 3_iPad } \\
\text { (Mean } \pm \text { S.E.) }\end{array}$ & $\begin{array}{c}\text { 4_Paper } \\
\text { (Mean } \pm \text { S.E.) }\end{array}$ \\
\hline $101 \times 1.03 \pm 0.02$ & $0.93 \pm 0.03$ & $0.96 \pm 0.03$ & $1.01 \pm 0.03$ \\
$301 \times 1.03 \pm 0.02$ & $0.98 \pm 0.03$ & $1.01 \pm 0.02$ & $0.98 \pm 0.02$ \\
$1001 \times 1.03 \pm 0.02$ & $0.96 \pm 0.03$ & $0.93 \pm 0.03$ & $1.02 \pm 0.02$ \\
$3001 \times 1.01 \pm 0.02$ & $0.99 \pm 0.03$ & $0.93 \pm 0.02$ & $1.01 \pm 0.02$ \\
$1,0001 \times 1.04 \pm 0.02$ & $1.00 \pm 0.02$ & $0.99 \pm 0.02$ & $0.99 \pm 0.02$ \\
$3,000 \times 1 \times 1.03 \pm 0.03$ & $1.01 \pm 0.02$ & $1.01 \pm 0.02$ & $1.10 \pm 0.02$ \\
\hline
\end{tabular}

TValues in the same column with the same letters are significantly different $(p<0.05)$ using ANOVA \& the Scheffé multiple comparison procedure

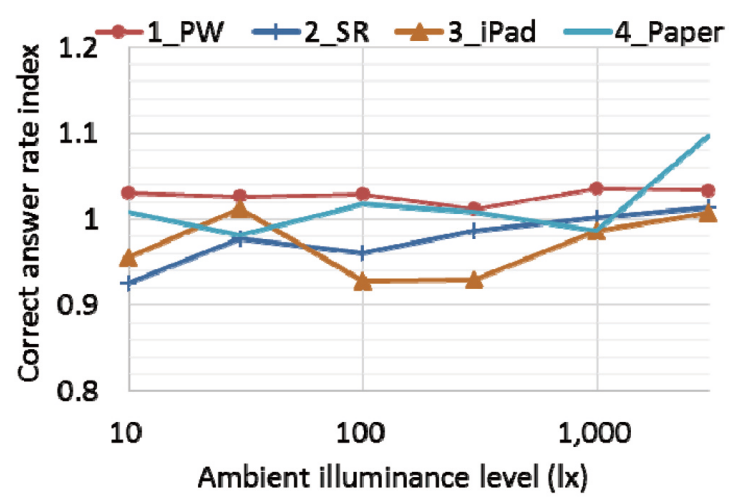

Fig. 4-3 The correct answer rate index under six illuminance levels

each illuminance. Table 3-1 and Figure 5-1 show a comparison of the young group's VAS for each level of illuminance. No significant differences were observed among the illuminance levels with the PW, SR and iPad. The VAS for Paper showed significant differences $(\mathrm{p}<$ 0.05 ) between $10 \mathrm{~lx}$ and more than 1,000 lx, and between $30 \mathrm{~lx}$ and 3,000 lx. In comparison, the subjects rated Paper better than the SR under the illumination conditions higher than $300 \mathrm{~lx}$, and better than the PW under the illumination conditions higher than 1,000 lx. The evaluation of Paper was the best in the 3,000 lx condition. The difference between the iPad and Paper in the subjects' evaluations under the 3,000 lx illuminance condition tended to be larger in the young group than in the other age groups.

Table 3-2 and Figure 5-2 show a comparison of the middle-aged group's VAS for each illuminance. There was no significant difference among illuminance levels for the iPad. The VAS for the PW showed significant differences $(\mathrm{p}<0.05)$ between $10 \mathrm{~lx}$ and more than 1,000 $\mathrm{lx}$, and between $30 \mathrm{~lx}$ and more than 1,000 $\mathrm{lx}$ illuminance. The VAS for the SR showed significant differences $(\mathrm{p}<0.05)$ between $10 \mathrm{~lx}$ and more than 1,000 $\mathrm{lx}$, between $30 \mathrm{~lx}$ and more than 1,000 lx, and between 
Table 3-1 Subjects' evaluations in the Young group using four devices under six ambient illuminance levels

\begin{tabular}{rcccc}
\hline $\begin{array}{c}\text { Ambient } \\
\text { illuminance }\end{array}$ & $\begin{array}{c}\text { 1_PW } \\
\text { (Mean } \pm \text { S.E.) }\end{array}$ & $\begin{array}{c}\text { 2_SR } \\
\text { (Mean } \pm \text { S.E.) }\end{array}$ & $\begin{array}{c}\text { 3_Pad } \\
\text { (Mean } \pm \text { S.E.) }\end{array}$ & $\begin{array}{c}\text { 4_Paper } \\
\text { (Mean } \pm \text { S.E. })\end{array}$ \\
\hline $101 \times 42.17 \pm 6.28$ & $16.29 \pm 10.49$ & $53.50 \pm 4.47$ & $19.20 \pm 6.58^{\mathrm{a}, \mathrm{b}}$ \\
$301 \times 43.00 \pm 4.73$ & $27.10 \pm 6.98$ & $55.67 \pm 4.25$ & $25.40 \pm 5.27^{\mathrm{c}}$ \\
$1001 \times 42.08 \pm 3.97$ & $34.80 \pm 5.20$ & $54.75 \pm 4.48$ & $32.50 \pm 4.45$ \\
$3001 \times 44.83 \pm 2.99$ & $38.58 \pm 4.25$ & $55.42 \pm 5.37$ & $45.67 \pm 6.47$ \\
$1,0001 \times 44.00 \pm 3.47$ & $44.42 \pm 4.81$ & $54.42 \pm 6.20$ & $53.42 \pm 5.54{ }^{\mathrm{a}}$ \\
3,000 1x $41.75 \pm 4.99$ & $49.17 \pm 6.44$ & $45.92 \pm 6.36$ & $59.42 \pm 6.37 \mathrm{~b}, \mathrm{c}$ \\
\hline
\end{tabular}

TValues in the same column with the same letters are significantly different $(p<0.05)$ using ANOVA \& the Scheffé multiple comparison procedure

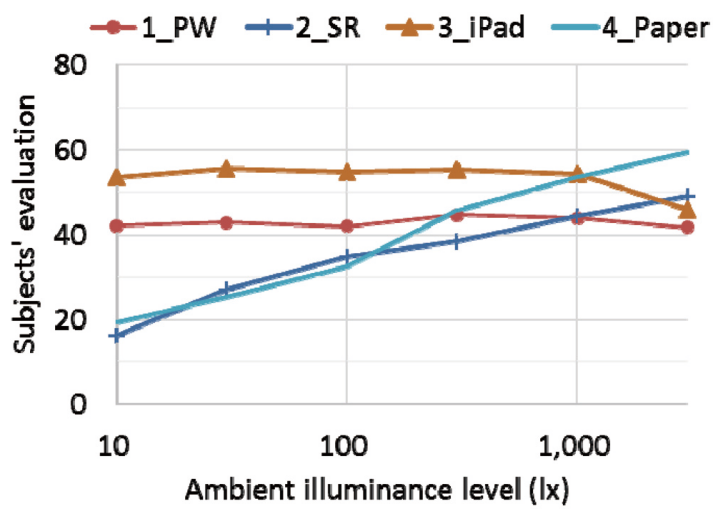

Fig. 5-1 VAS of the Young group under six illuminance levels

Table 3-2 Subjects' evaluations in the Middle-aged group using four devices under six ambient illuminance levels.

\begin{tabular}{|c|c|c|c|c|c|}
\hline $\begin{array}{c}\text { Ambient } \\
\text { illuminance }\end{array}$ & $\begin{array}{c}\text { 1_PW } \\
(\text { Mean } \pm \text { S.E. })\end{array}$ & & $\begin{array}{c}\text { 2_SR } \\
\text { Mean } \pm \text { S.E.) }\end{array}$ & $\begin{array}{c}\text { 3_iPad } \\
(\text { Mean } \pm \text { S.E.) }\end{array}$ & $\begin{array}{c}\text { 4_Paper } \\
\text { (Mean } \pm \text { S.E.) }\end{array}$ \\
\hline $101 \times 22.46$ & $6 \pm 1.70 a, b$ & 5.25 & $\pm 1.71 a, b$ & $38.42 \pm 4.14$ & $13.38 \pm 2.40^{a}$ \\
\hline $301 \times 25.27$ & $7 \pm 1.93 \mathrm{c}, \mathrm{d}$ & 18.90 & $\pm 4.46 \mathrm{c}, \mathrm{d}$ & $44.67 \pm 4.53$ & $29.09 \pm 6.92$ \\
\hline $100 \mathrm{~lx} 35.00$ & $0 \pm 5.02$ & 27.90 & $0 \pm 4.18 \mathrm{e}$ & $48.92 \pm 4.71$ & $40.73 \pm 6.57$ \\
\hline $300 \mathrm{~lx} 41.50$ & $0 \pm 5.27$ & 35.67 & $7 \pm 4.10$ & $60.83 \pm 5.10$ & $45.00 \pm 7.87$ \\
\hline $1,000 \mathrm{~lx} 48.58$ & $8 \pm \pm 4.78$ a,c & 50.00 & $0 \pm 4.40$ a,c & $64.00 \pm 6.38$ & $48.67 \pm 6.75$ \\
\hline $3,000 \mathrm{~lx} 51.50$ & $0 \pm 5.63 b, c$ & 54.42 & $\pm 5.16 \frac{b, d}{e}$ & $56.58 \pm 7.03$ & $58.42 \pm 5.99{ }^{a}$ \\
\hline
\end{tabular}

TValues in the same column with the same letters are significantly different $(\mathrm{p}<0.05)$ using ANOVA \& the Scheffé multiple comparison procedure

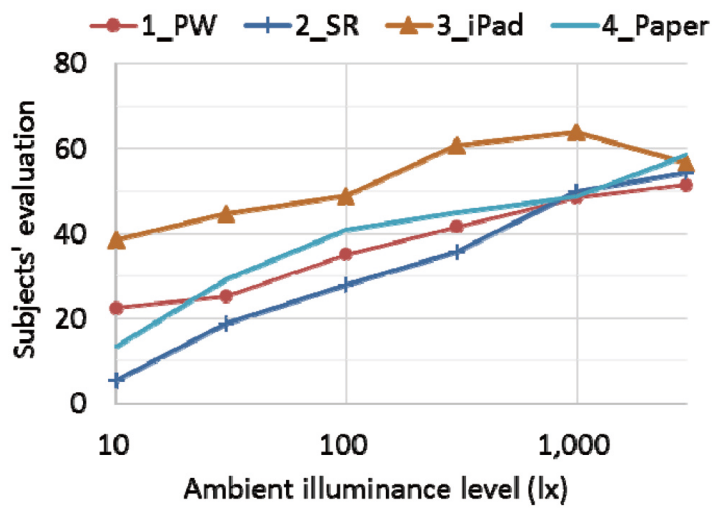

Fig. 5-2 VAS of the Middle-aged group under six illuminance levels
$100 \mathrm{~lx}$ and 3,000 lx. The VAS for Paper showed significant differences $(\mathrm{p}<0.05)$ between $10 \mathrm{~lx}$ and 3,000 lx. In comparison, the subjects evaluated Paper as better than the other devices in the 3,000 lx illuminance condition.

Table 3-3 and Figure 5-3 show a comparison of the senior middle-aged group's VAS for each illuminance. No significant differences were observed among the illuminance levels with the PW and iPad. The VAS for the SR showed significant differences $(\mathrm{p}<0.05)$ between $10 \mathrm{~lx}$ and more than $300 \mathrm{~lx}$, between $30 \mathrm{~lx}$ and more than 1,000 lx, and between $100 \mathrm{~lx}$ and 3,000 lx. The VAS for Paper showed significant differences $(p<0.05)$ between $10 \mathrm{~lx}$ and more than $100 \mathrm{~lx}$, and between $30 \mathrm{~lx}$ and more than $300 \mathrm{~lx}$, and between $100 \mathrm{~lx}$ and more than 1,000 lx. In comparison, the subjects evaluated Paper higher than the PW and iPad under the illuminance conditions higher than 1,000 lx, and higher than the SR at all illuminance levels. The slopes of the line graph in Figure 5-3 for the SR and Paper show similar movements and were affected more than the PW and iPad by the illuminance levels.

Table 3-3 Subjects' evaluation in the Senior middle-aged group using four devices under six ambient illuminance levels.

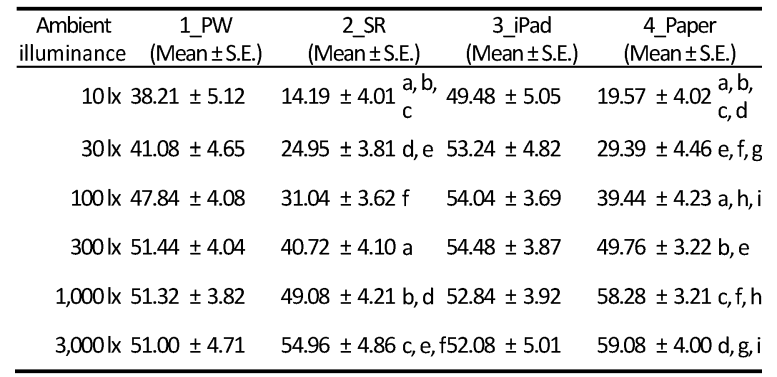

TValues in the same column with the same letters are significantly different $(p<0.05)$ using ANOVA \& the Scheffe multiple comparison procedure

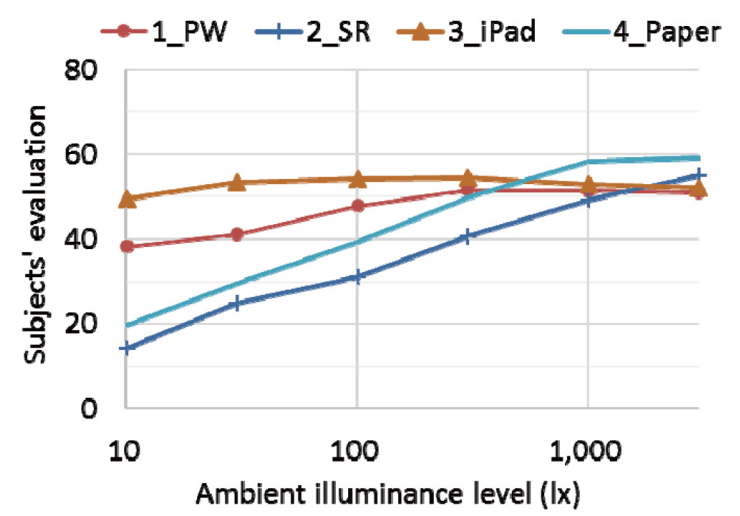

Fig. 5-3 VAS of the Senior middle-aged group under six illuminance levels 
Table 3-4 Subjects' evaluations in the Elderly group using four devices under six ambient illuminance levels.

\begin{tabular}{|c|c|c|c|c|}
\hline $\begin{array}{c}\text { Ambient } \\
\text { illuminance }\end{array}$ & $\begin{array}{c}\text { 1_PW } \\
(\text { Mean } \pm S . E .)\end{array}$ & $\begin{array}{c}\text { 2_SR } \\
(\text { Mean } \pm \text { S.E. })\end{array}$ & $\begin{array}{c}\text { 3_iPad } \\
(\text { Mean } \pm \text { S.E. })\end{array}$ & $\begin{array}{c}\text { 4_Paper } \\
(\text { Mean } \pm \text { S.E.) }\end{array}$ \\
\hline $10 \mathrm{~lx}$ & $1.50 \pm 4.45 a, b$ & $\pm 1.54 \mathrm{a}, \mathrm{b}$ & $=37.89 \pm 5.94$ & $10.33 \pm 2.35 \mathrm{a}, \mathrm{b}, \mathrm{c}$ \\
\hline $30 l x$ & $4.00 \pm 5.71$ & $14.44 \pm 3.04 \frac{d}{f}, e$ & $41.22 \pm 6.08$ & $22.11 \pm 3.26 \mathrm{~d}, \mathrm{e}, \mathrm{f}$ \\
\hline $100 \mathrm{~lx}$ & $7.67 \pm 6.12$ & $23.56 \pm 3.75 \mathrm{~g}, \mathrm{~h}$ & $45.33 \pm 7.18$ & $32.78 \pm 5.38 \mathrm{~g}, \mathrm{~h}$ \\
\hline $300 \mathrm{~lx}$ & $1.11 \pm 5.01$ & $31.78 \pm 3.92_{j}^{a, c}$ & $53.56 \pm 6.89$ & $50.67 \pm 5.31 \mathrm{a}, \mathrm{d}$ \\
\hline $1,000 \mathrm{~lx}$ & $0.89 \pm 5.64 a$ & $49.00 \pm 3.39 \mathrm{~b}, \mathrm{e}$, & $55.00 \pm 8.26$ & $59.78 \pm 4.22 \mathrm{~g}$ \\
\hline $3,000 \mathrm{~lx}$ & $.11 \pm 5.16 b$ & $53.78 \pm 2.50^{C,}$ & \pm 7.10 & $58.67 \pm 5.26 c, f, h$ \\
\hline
\end{tabular}

TValues in the same column with the same letters are significantly different $(\mathrm{p}<0.05)$ using ANOVA \& the Scheffé multiple comparison procedure

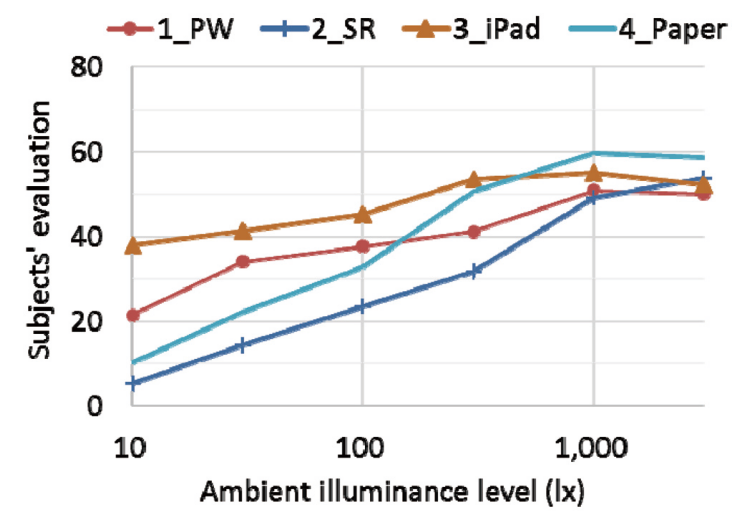

Fig. 5-4 VAS of the Elderly group under six illuminance levels

Table 3-4 and Figure 5-4 show a comparison of the elderly group's VAS for each illuminance. There was no significant difference among illuminance levels for the iPad. The VAS for the PW showed significant differences $(\mathrm{p}<0.05)$ between $10 \mathrm{~lx}$ and more than 1,000 lx. The VAS for the SR showed significant differences $(\mathrm{p}<0.05)$ between $10 \mathrm{~lx}$ and more than $300 \mathrm{~lx}$, between $30 \mathrm{~lx}$ and more than $300 \mathrm{~lx}$, between $100 \mathrm{~lx}$ and more than 1,000 $\mathrm{lx}$, and between $300 \mathrm{~lx}$ and more than 1,000 lx. The VAS for Paper showed significant differences $(p<0.05)$ between $10 \mathrm{~lx}$ and more than $300 \mathrm{~lx}$, between $30 \mathrm{~lx}$ and more than $300 \mathrm{~lx}$, and between $100 \mathrm{~lx}$ and more than $1,000 \mathrm{~lx}$. In comparison, the subjects rated Paper higher than the PW under illuminance conditions higher than $300 \mathrm{~lx}$, higher than the iPad under illuminance conditions higher than 1,000 lx, and higher than the SR at all levels. The slopes of the line graph in Figure 5-4 for the SR and Paper show similar movements and were affected more than the PW and iPad by the illuminance levels.

\subsection{Evaluations by devices}

Figures 6-1, 6-2, 6-3 and 6-4 show comparisons of subjects' device-specific evaluations (VAS) for each level of illuminance. We used the same data from figures 5-1,

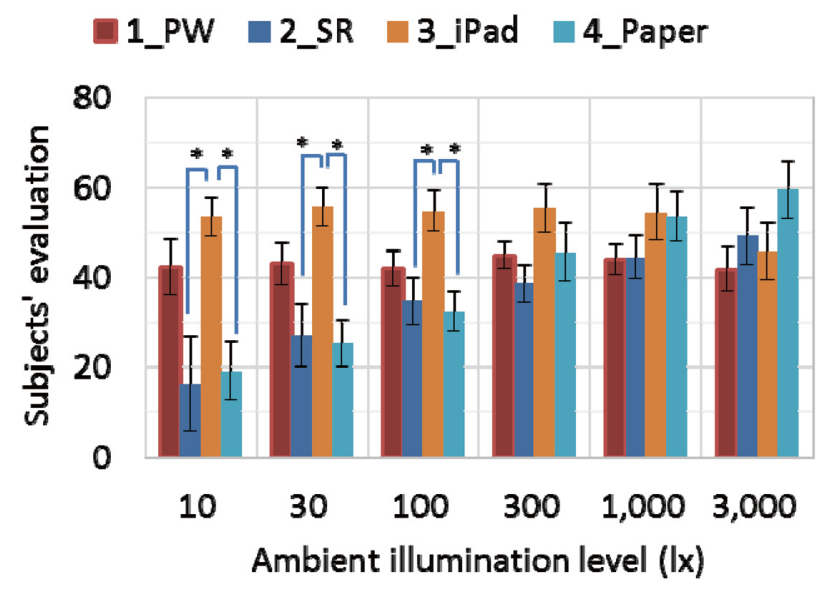

Fig. 6-1 VAS in the Young group under six illuminance levels $(*: \mathrm{p}<0.05)$

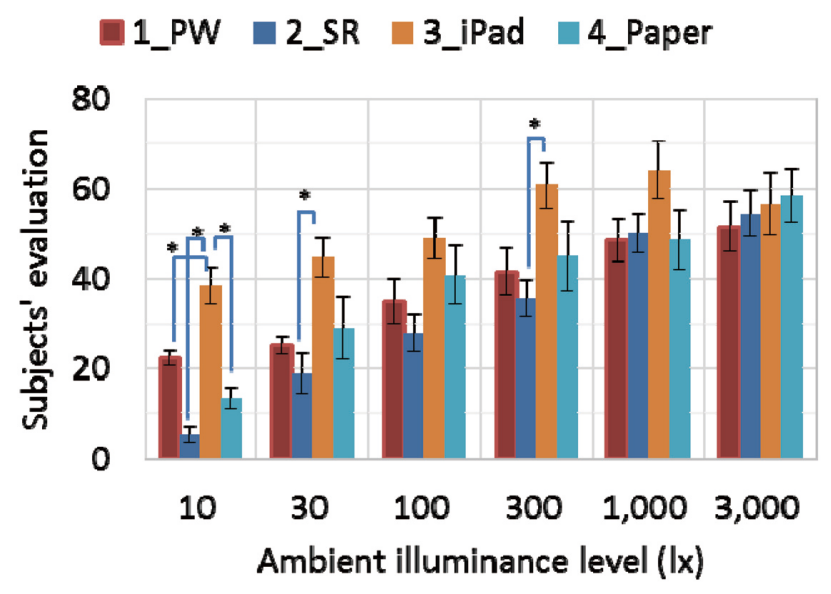

Fig. 6-2 VAS in the Middle-aged group under six illuminance levels $(*: \mathrm{p}<0.05)$

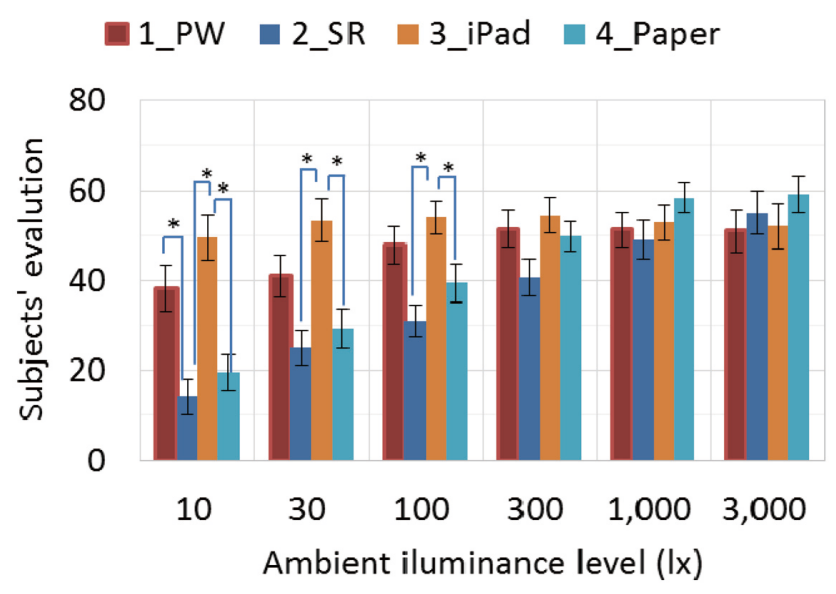

Fig. 6-3 VAS in the Senior middle-aged group under six illuminance levels $(*: \mathrm{p}<0.05)$

5-2, 5-3 and 5-4 to evaluate the differences among devices. The mean scores for the iPad showed the best rating under illuminance conditions lower than $300 \mathrm{~lx}$ for all ages. There was no significant difference in the ratings for all devices under illuminance conditions 


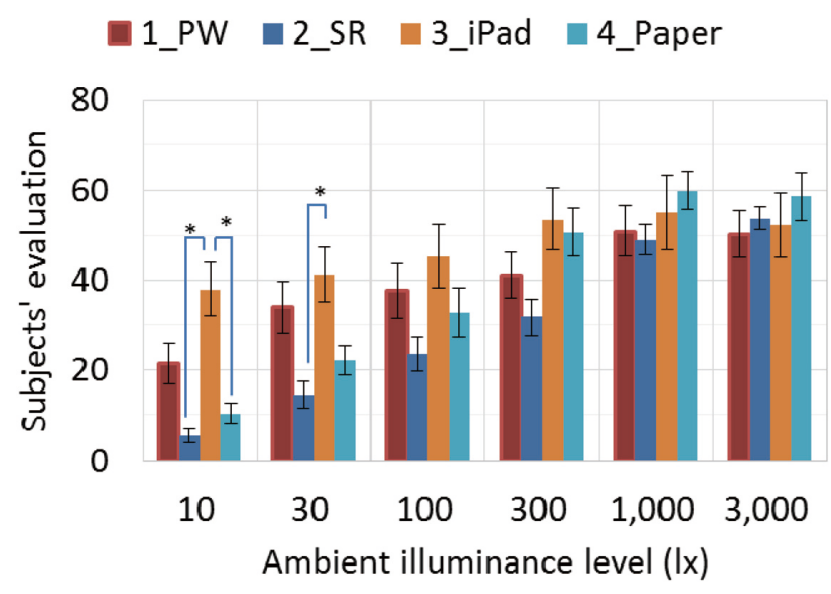

Fig. 6-4 VAS in the Elderly group under six illuminance levels $(*: \mathrm{p}<0.05)$

higher than $300 \mathrm{~lx}$ with the exception of a difference between the evaluation of the iPad and SR by the middle-aged group. The mean scores for the SR without a front light were better than the scores for the PW with a front light for 3,000 lx in all ages.

\section{Discussion}

In this study, we used three indexes (VAS, reading time index, and correct answer rate index) to evaluate the readability of several devices. The illuminance level and type of device affected the VAS and reading time index; however, they had a low impact on the correct answer rate index. We confirmed that when the subjects rated readability as poor, they tended to read slowly and more accurately. In our previous studies, we found that there was an upper limit to the number of words that subjects could read aloud under illuminance of $300 \mathrm{~lx}$ with e-papers ${ }^{2)}$ 8). This study showed that subjective performances declined with decreasing illuminance and that there was almost no significant difference in the subjective evaluations under illuminance conditions of higher than $300 \mathrm{~lx}$ with all devices. On the basis of prior studies (Lee et al. ${ }^{9)}$ and Kojima et al. ${ }^{10)}$ ) and this study, we suggest that illuminance of $300 \mathrm{~lx}$ is the limiting lighting level at which subjects can maintain their performance. The ISO ${ }^{11)}$ recommends a level of $500 \mathrm{~lx}$ for indoor reading; therefore, we consider the ISO recommendation to be reasonable and proper. In a previous study ${ }^{8}$, we showed the possibility of establishing a baseline score of 45 for VAS to indicate whether subjects have reached a sufficient level of reading of a text. In this study, the mean score for the VAS among all ages under illuminance conditions of 300 lx was $47.043 \pm 1.30$ (Young group: $46.125 \pm 2.62$, Middle-aged group: $45.75 \pm 3.18$, Senior middle-aged group: $49.1 \pm 1.98$, Elderly group: $44.278 \pm 3.05$ ). Taken together, our studies indicate that it is possible to set a baseline showing that subjects reach a sufficient readability level at a score of between 45 and 47 .

With regard to the evaluations by age groups, the ambient illuminance had a greater impact on older age groups than the younger age groups with devices without lighting systems in the lower illuminance conditions. The elderly group's evaluations for all devices decreased substantially in the lower levels of illuminance, while the younger group found less difficulty in reading under these conditions. This difference could be related to cloudiness in the eye lens of many elderly subjects ${ }^{12}$. In addition, we previously reported $^{12)}$ that the lighting systems of e-paper readers improved subjects' evaluation in the lower illuminance conditions. For these conditions, we suggested that the lighting systems of e-paper readers contributed to improving readability in older groups in the lower illuminance levels.

With regard to the evaluations by devices, as with our previous studies ${ }^{1)}$ ), in this study we found that the changes in the readability of reflective e-paper under various illuminance conditions were similar to those for paper text, and this tendency was remarkable in the older groups. The backlit LCD has its own light source and has a high resolution and contrast ratio, and no significant differences in reading were seen at any of the levels of illuminance. However, the evaluations for the backlit LCD were comparable in score to that for the paper text at 1,000 lx illuminance condition, while the best rating at 3,000 lx illuminance was obtained with the paper text. This result was similar to that of our previous study ${ }^{1}$. This study confirmed the superiority of built-in light systems under illuminance conditions of less than 1,000 lx compared to reflective devices, which was also similar to our previous study under illuminance conditions of less than $750 \mathrm{~lx}^{2}$. As the subjects' evaluation for self-luminescent devices, especially by younger groups, tended to decrease with illuminance of 3,000 lx, improvement of readability under higher outdoor lighting levels remains as an issue to be solved.

\section{Conclusion}

This study investigated the effects of ambient illuminance and aging on the readability of e-papers. We summarize the findings as follows:

(1) Illuminance of $300 \mathrm{~lx}$ was the limiting lighting level at which subjects could maintain their 
performance.

(2) The various ambient illuminance levels affected the readability among all ages, and had a greater impact on the older age groups than the younger age groups.

(3) The lighting systems of e-paper readers contributed to improving readability for the older group in the lower illuminance conditions.

(4) As the readability of self-luminescent devices tended to decrease with illuminance of 3,000 lx, these devices should perhaps not be recommended for use under higher outdoor lighting levels.

\section{[References]}

1) T. Koizuka, S. Sano, T. Kojima, M. Miyao: "Evaluating the Effects of Environmental Illuminance on the Readability of E-books", SID Symposium Digest of Technical Papers, pp. 571 - 573 (2013)

2) T. Koizuka, Y. Ishii, T. Kojima, R.P. Lege, M. Miyao, ÅgThe Contributions of Built-in Light on the Readability in E-paper Devices", SID Symposium Digest of Technical Papers, 45, pp. 861864 (2014)

3) S. Ueki, T. Taguchi, K. Nakamura, Y. Itoh, K. Okamoto: "New Metrics Based on Visual Perception for Evaluating Image Quality", Proceedings International Display Workshops, 1, pp. 519-522 (2006)

4) Amazon.com - Kindle Paperwhite Touch Screen E-reader with Light, http://www.amazon.com/Kindle-Paperwhite-Ereader/dp/ B00AWH595M

5) SONY - SONYReader http://www.sony.jp/reader/products/PRS-T3S/

6) Apple - iPad, http://support.apple.com/kb/SP647

7) ISO 9241-304, User performance test methods for electronic visual displays, International Organization for Standardization (2008)

8) T. Koizuka, Y. Ishii, T. Kojima, N. Ishio, R.P. Lege, M. Miyao: "Proposing a Baseline Setup for Readability", IDW 2014, Niigata, Japan (Dec. 3-5, 2014)

9) D. Lee, K. Shieh, S. Jeng, I. Shen: "Effects of character size and lighting on legibility of electronic paper", Displays, pp. 10-17 (2008)

10) T. Kojima, S. Sano, N. Ishio, T. Koizuka, M. Miyao: "Verification of the Minimum Illuminance for Comfortable Reading of an E-paper", Universal Access in Human-Computer Interaction. Application and Services for Quality of Life Lecture Notes in Computer Science, 8011, pp. 348-355 (2013)

11) ISO 8995-1:2002 (CIE S 008/E:2001), Lighting of Work Places Part 1:

12) Y. Ishii, T. Koizuka, R. Cui, T. Kojima, M. Miyao: "Evaluation of Readability for Tablet Devices by the Severity of Cataract Cloudiness", SID Symposium Digest of Technical Papers, 45, 1, pp. 1089-1092 (2014)

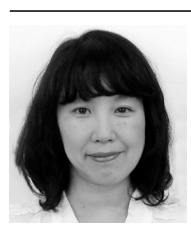

Shigusa Matsunami obtained her master's degree in Agricultural Science from Nagoya University in 1994. She has worked for Aichi prefectural government since then. Currently she is a graduate student in the Department of Information Systems, Graduate School of Information Science, Nagoya University. She is researching readability of E-paper under various conditions.

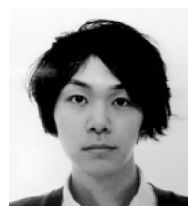

Tatsuya Koizuka is a graduate student in the Department of Information Systems, Graduate School of Information Science, Nagoya University. He is studying the visibility and readability of E-papers under various conditions, such as different illuminance.

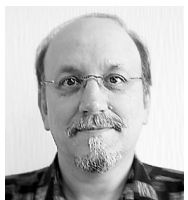

R. Paul Lege obtained his Master's degree in Humanities from California State University in 2003 Currently, he is a designated associate professor in the Graduate School of Law at Nagoya University. In addition, he has worked with the Department of Information Science concerning the effects of illuminance on reading.

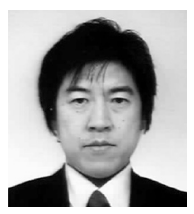

Takehito Kojima obtained his $\mathrm{PhD}$ in Information Science, Graduate School of Information Science, Nagoya University in 2013. Currently, he is an assistant professor at Chubu-gakuin University, and is researching human interface of $3 \mathrm{D}$ displays and $\mathrm{E}$ papers.

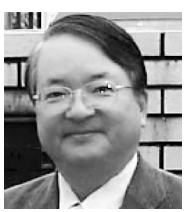

Masaru Miyao obtained his $\mathrm{PhD}$ in medical science in 1985, Graduate School of Medicine, Nagoya University; BMS in 1977, School of Medicine Nagoya University; and MD in 1977. Currently, he is a professor at the Graduate School of Information Science, Nagoya University. His field of specialty is ergonomics and industrial health, and his current research focus is on the human interface of $3 \mathrm{D}$ displays and E-papers. 